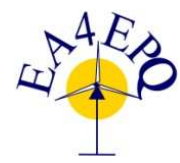

International Conference on Renewable Energies and Power Quality (ICREPQ'13) Bilbao (Spain), 20 $0^{\text {th }}$ to $22^{\text {th }}$ March, 2013

Renewable Energy and Pourer Qualimy. Fournal (RE\&PQJ)

ISSN 2172-038 X, No.11, March 2013

\title{
Energy Planning Methodologies
}

\author{
T. Portela ${ }^{1}$ and J. Lafay ${ }^{1}$ \\ ${ }^{1}$ Post-graduate Program in Electrical Engineering (PPGEE) \\ UTFPR, Campus of Pato Branco \\ Via do Conhecimento Km 01, 85503-390, Pato Branco, PR, Brasil \\ Phone number: +55 4688011649 , e-mail: tarlis@tarlis.com.br, jeanmarc@utfpr.edu.br
}

\begin{abstract}
This paper considers the need for organizations to obtain an energy planning and exposes three methods to do so. Energy planning is part of a process of energy efficiency important for organizations to become more competitive. Even the recent standardization of energy management leads brazilian institutions to develop processes and methods for energy efficiency. There is still a gap being presented in the literature and the needs of these institutions. Although energy planning is only part of the energy management system, this text provides a compilation of information for the initial development of a methodology for the organization energy planning.
\end{abstract}

\section{Key words}

Energy Planning, Energy Management, Energy Efficiency, Standards, Indicators.

\section{Introduction}

It is understood by planning the determination of objectives of an enterprise as, also, the coordination of means and resources to achieve them. One could not speak planning without management and this concepts are rarely separated. Management encompasses the functions of planning, organization and control of the transformation process and its usefulness in providing a good or service to customers [1].

In 2001, Brazil suffered a crisis in the electricity sector the so-called "blackout crisis" - leading to power shortages, a reflection of an inefficient energy policy in force [2], [3]. A lack of planning can lead to serious problems for an industry or country, as the case cited. It is evident the need to care for planning and energy management of an institution when putting into perspective: the growth in consumption, the difficulty of storing energy; obsolete equipment and processes; the use of different energy sources; renewable energy sources; and public policies. Furthermore, it can be considered a possible charging for use of more polluting sources.
Conventional methods of production and use of energy generally incorporate harmful environmental impacts, and therefore the challenge for scientists in the search for mechanisms of production and use of energy that are free of adverse environmental impacts [4]. According to the authors, economic progress and sustainable development are linked to optimization and energy conservation.

The use of energy has always been linked to the degree of development of civilizations [3]. The author also describes that early civilizations used as main sources of biomass energy, strength and feed, the winds and water. Increasingly man can sharpen energy conversion, such as coal fueling the Industrial Revolution (XVIII century) marked by the creation of the steam engine.

After the discovery of oil in the end of century XIX, and later natural gas, coal is no longer the main source of energy consumed, but still playing an important role in the global energy mix. The field of electricity use gives new impetus to the development and generates a relationship of strong dependence on fossil fuels for energy generation [3].

In Brazil there was the use of biomass, animal traction and human strength, whale oil for lighting and coal by the end of the colonial period.

\section{Energy Policies}

According to [3], Brazil has gradually increased the consumption of oil until the two major oil shocks (in 7374 and 79-80) generated the perception that a new energy policy was necessary. The new policy included the following: increased oil drilling, increased production of coal in the country; launch of the Brazilian nuclear program, creation of the National Alcohol Program (Proalcool); continue the expansion of the hydro 
generator, and the realization of first programs of energy efficiency nationwide.

Policies have been established in several countries to promote energy efficiency, service quality and the search for cleaner energy solutions, ie, lower environmental impact and its more efficiently usage.

Therefore, is created the normative ISO 50001: the purpose of this standard is to enable organizations to establish systems and processes necessary to improve energy performance, including efficiency, use and consumption of energy. It is expected that implementation of this standard will lead to reductions in emissions of greenhouse gases, energy costs and other associated environmental impacts through systematic management of energy [5].

\section{The Deployment of ABNT NBR ISO 50001}

The ISO 50001 standard specifies the requirements for an energy management system (EMS) for an organization to develop and implement an energy policy, establish objectives, targets and action plans which consider legal requirements and information on meaningful use of energy [5]. The standard describes the need for the institution to create energy policies and planning, implementation and operation, checking and reviewing results.

The proposed model follows a continuous improvement methodology called Plan-Do-Check-Act (PDCA). Figure 1 presents a model of PDCA methodology used in energy management by Toyota.

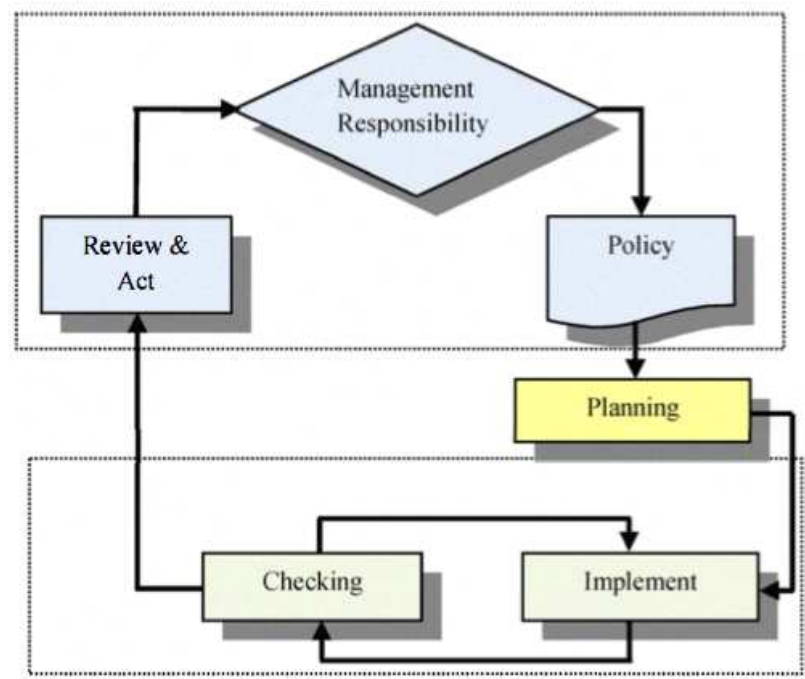

Fig. 1: Structure of the continuous improvement methodology Plan-Do- Check-Act (PDCA) used by Toyota. Source: [6]

The PCDA can be characterized as follows, as specified in the same standard:

1) Plan: determination of organizations' energy performance (stage of energy review) and establishment of energy performance indicators baseline (IDEs), objectives, targets and action plans;

2) Do: implement the action plans of energy management;

3) Check: monitor and measure processes and characteristics of the operations, and disseminate results;

4) Act: take actions to continually improve energy performance and energy management system (EMS).

Firstly, one must make a survey of the energy situation of the organization (energy review) so that can be the baseline and, at the end of the cycle, it is compared with the situation after implementation of the EMS. The measure of the organizational energy situation can be made using indicators. For reference see Table I that displays some energy efficiency indicators, reported by [1].

The energy planning methodology defined by ABNT NBR ISO 50001 is shown in Figure 2.

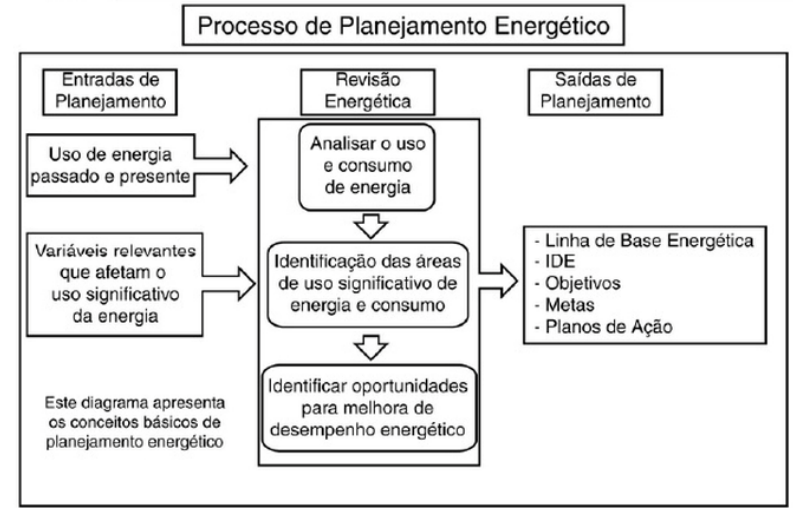

Fig. 2: Conceptual diagram of the energy planning process. Source: [5]

\section{A. Planning Process}

According to the standard [5], the organization should develop, register and keep its Energy Review. It can be done in three steps:

1) Consumption analysis: identify current energy sources and evaluate current and past energy use;

2) Identify areas that significantly affect the use and consumption of energy:

- In facilities, equipment, systems, processes and people;

- Determine the current energy performance of the same;

- Identify future energy usage and consumption.

3) Identify opportunities for improvement. May be potential sources of energy, renewable and alternative sources. 
Table I. - List of energy efficiency indicators developed by the us environmental protection agency (US EPA). Source: [1]

\begin{tabular}{|c|c|c|c|}
\hline Indicator & Indicator's type & Use & Formula/Unit \\
\hline Energy intensity & Economic & Aggregated level & Energy consumption / economic term \\
\hline Specific energy consumption & Physical & Disaggregated level & GJ per $\mathrm{t}$ \\
\hline Energy intensity & Macro-economic & Aggregated level & Energy consumption / monetary variables (GDP) \\
\hline Degree of efficiency & Engineering view & Aggregated level & Net energy/used primary energy \\
\hline Final energy efficiency improvement & Physical & National level & Energy savings per year \\
\hline Thermodynamic energy efficiency & Thermodynamic & $\begin{array}{l}\text { Measurements } \\
\text { derived from the } \\
\text { science of } \\
\text { thermodynamics }\end{array}$ & Actual energy usage related to an 'idealprocess' \\
\hline $\begin{array}{l}\text { Physical-thermodynamic energy } \\
\text { efficiency }\end{array}$ & Hybrid & $\begin{array}{l}\text { Measure the service or } \\
\text { delivery of the process }\end{array}$ & Actual energy usages/tonnes or passenger miles \\
\hline $\begin{array}{l}\text { Economic-thermodynamic energy } \\
\text { efficiency }\end{array}$ & Hybrid & $\begin{array}{l}\text { Measure the service or } \\
\text { delivery of the process }\end{array}$ & $\begin{array}{l}\text { Energy usage in conventional thermodynamic } \\
\text { units/output in terms of market price }\end{array}$ \\
\hline Economic energy efficiency & Economic & $\begin{array}{l}\text { Measure in terms of } \\
\text { market value }\end{array}$ & $\begin{array}{l}\text { Energy input in monetary terms/output in monetary } \\
\text { terms }\end{array}$ \\
\hline Energy efficiency measurement & Economic & Activity of a sector & $\begin{array}{l}\text { Energy consumption/value added or value of } \\
\text { shipments }\end{array}$ \\
\hline Specific energy consumption & Physical & $\begin{array}{l}\text { Process level, cross } \\
\text { country comparison }\end{array}$ & Energy use/physical unit of production \\
\hline $\begin{array}{l}\text { Thermal energy efficiency of } \\
\text { equipment }\end{array}$ & Physical & For single equipment & $\begin{array}{l}\text { Energy value available for production/input energy } \\
\text { value }\end{array}$ \\
\hline Energy consumption intensity & Physical & $\begin{array}{l}\text { Broader than thermal } \\
\text { indicator: companies, } \\
\text { etc. }\end{array}$ & Energy consumption/physical output value \\
\hline $\begin{array}{l}\text { Absolute amount of energy } \\
\text { consumption }\end{array}$ & Physical & $\begin{array}{l}\text { With indication of } \\
\text { production volumes }\end{array}$ & Energy value \\
\hline Diffusion rates of equipment & Physical & $\begin{array}{l}\text { Focusing on specific } \\
\text { energy efficient } \\
\text { technology }\end{array}$ & Rate of deployment of technology \\
\hline Industrial energy intensity & Physical & $\begin{array}{l}\text { Comparison of } \\
\text { efficiency data on a } \\
\text { subsector level } \\
\text { between countries. }\end{array}$ & Energy use/unit of industrial output, e.g., GJ/t \\
\hline Specific energy consumption & Physical & On sector level & e.g., GJ/t \\
\hline Energy performance indicator & Statistical & On plant level & Percentile ranking of the energy efficiency \\
\hline
\end{tabular}

Based on the results the organization will establish a energy baseline to changes in performance be compared to defined baselines. Adjustments should also be made to baselines when: indicators no longer reflect the use and power consumption of the organization; there are significant changes in processes, operating standards or energy systems; or, when there is a predetermined method.

The Energy Performance Indicators should be identified and monitored regularly. So, these indicators are recorded and compared to baseline when appropriate.

The organization ultimately must document and establish energy objectives, energy goals and action plans for energy management. Action plans need to meet the goals and objectives outlined and include:

1) Assignment of responsibilities;

2) Means and schedules for each individual goal;

3) Method by which the performance improvement will be checked;

4) Method for checking results.

\section{The Jordanger Model}

Reference [7] presents a methodology for the design of complex systems and local distribution of energy as well as the foundation for a new thinking. For governments and manufacturing companies, the global warming, the rising energy prices and increasing environmental awareness of customers led to efficient energy production to the top of the agenda. Governments and companies are struggling to identify the most effective measures to increase energy efficiency in production processes [7], [1].

According to such model, the author identifies four stages in the process of power management:

1) Problem formulation, establishment of premisses and criteria to be utilized;

2) Gathering relevant data related to demand forecasting, resource mapping, available technologies, etc.; 
3) Analysis of relevant alternatives (technically, economic and environmental);

4) Decision making (evaluation, negotiation, acceptance, etc.).

The author highlights the growing focus on renewable and distributed generation makes necessary an analysis of alternative energy carriers in combination with each other. And also that the distribution units possibly have suboptimized solutions. It also identifies the environmental impact caused by most energy matrices may include: emissions, noise, aesthetic impact, among others, and although all impact on nature, the entire life cycle of these impacts should be included in the analysis.

It is also worth noting that the possibility of energy costs inclusion on this analysis and possible subsidies and tariffs for alternative energy. Of course the economic criterion is possibly the most important in most decisions. Finally, the author divide his process into the following steps:

1) Based on a library of available components, the user creates a system model of energy service(s) with alternative solutions to be optimized. Available energy resources are collected, processed, stored and transported in different ways and places before being converted into energy as desired end-user electricity and heat. The model treats the transport of energy in pipeline and power line as well as by road;

2) The user enters the required parameters for each component related to cost, lifetime, efficiency, emissions and relevant technical parameters specific to each component;

3) The network connection is composed of a simple and unambiguous set of variables such as the cost of energy flow and emissions;

4) The model is then mapped to a generic network (graph) of nodes and branches;

5) Optimization is done on this general graph model, where the energy is flowing.

\section{The Bunse Model}

The same manner as [7], author [1] highlights the reasons for improvements in energy efficiency due to the increase in prices, costs over $\mathrm{CO} 2$ emissions and demand for goods and "green origin" services by customers. These pillars are shown in Figure 3.

Energy is a significant strategic issue related to economic development, social stability and national security of the country, is also a focus point, that every aspect of society pay attention [8].

Bunse defines "energy management" as applying to resources, as well as for the supply, conversion and use of energy. Essentially, it involves monitoring, measurement, record-ing, analysis, critically examination, control and redirecting the flows of energy and materials through systems so that less energy is expended to achieve valid goals .

The Bunse model, being detailed, is divided into four parts: a measure of efficiency, control and improvement of the same, ICT enables efficient energy production and standardization enabling efficient energy production. The format of this management methodology is described in Figure 4.

The author also defines the need for the organization to maintain a continuous search for the future and the gap between literature and the needs of industry.

\section{A. Energy Efficiency Measure}

To define the energy efficiency of the organization is necessary to measure the Key Performance Indicators. The energy consumption of a process enables access to potential optimization and visualization of benefits to improving measures. Generally the indicators describe the relationship between the activity and energy required.

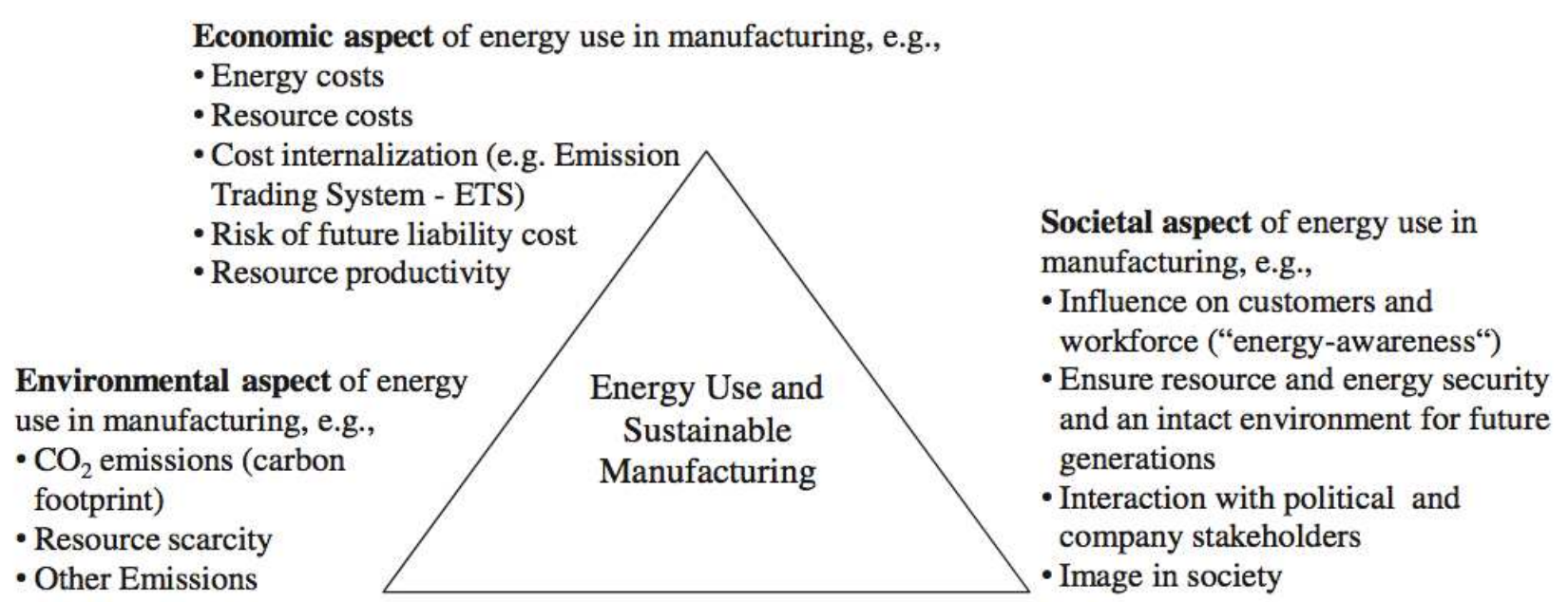

Fig. 3. Contribution of energy efficiency for the three fundamental aspects of sustainable manufacturing. Source: [1] 


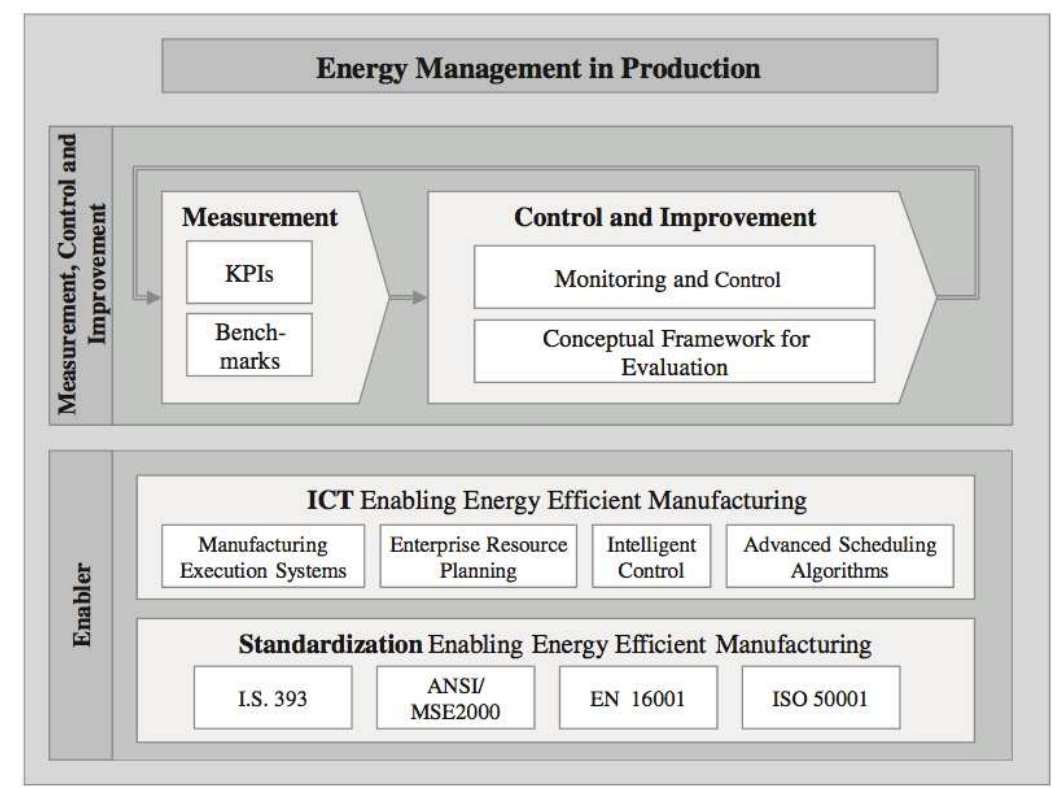

Fig. 4: Energy management in production. Source: [1]

Subsequently are made Benchmarks, i.e., measurements and comparisons, it can be a complex task because of conflicting performance criteria and a large variety of assessment criteria available.

\section{B. Control and Improving Energy Efficiency}

The second part defined by Bunse, is also characterized by two processes [1]:

1) Monitoring and controlling: includes monitoring of energy efficiency, benchmarks and audits. The last, in particular, allows those responsible for decision making to identify opportunities for improvement and monitor the effects of their decisions over the energy use;

2) Conceptual points for evaluation: the base for relevant decisions in the evaluations of energy efficiency measures is the definition and the development of appropriate indicators.

The lack of monitoring results in organizations unable to identify potential investments in energy. Moreover, they find it difficult to assess the effectiveness by the lack of appropriate concepts, as already mentioned, the definitions of indicators is not an easy task [1].

\section{ICT Enabling Efficient Energy Production}

ICT (Information and Communication Technologies) can help manage and reduce energy consumption in manufacturing processes. It can support the control of production processes, as well as validation and assessment of potential savings in energy investments [1]. Some of these technologies may be cited as: ERP (Enterprise Resource Planning), CRM (Customer Relationship Management) and PLM (Product Lifecycle Management).

\section{Standardization enabling efficient energy production}

Standardization increases transparency of business processes and stakeholders can more easily evaluate a company's commitment to improving its environmental performance. In this part of the process, management standards aimed at enhancing the environmental performance and energy efficiency of a company, improving the organization's processes [1]. Examples of standardization may be cited standards: ISO 50001, ISO 9001 and ISO 14001

\section{Conclusion}

This paper puts into perspective some energy planning methodologies, however, which may make it more difficult to implement a methodology is its generality. That is, for an organization, not to specifying details regarding the manner of deployment of these techniques makes it difficult to take actions.

The normative ABNT 50001 presents its methodology in a superficial way, leading to the search of procedures, indicators and techniques to develop an own method of energy management. The other methodologies, however are also presented superficially, for being similar, provide information that can supplement the existing information gap.

It is necessary to highlight the difficulty that organizations can find at the moment they are defining its energy efficiency indicators. So few of these evaluation criteria can be found in the literature (as cited by [1]). However, these performance criteria are key to develop a evaluation method for the results obtained with energy management. 


\section{Acknowledgement}

The authors acknowledge FINEP, CAPES, SETI, CNPq and Fundação Araucária, for scholarships and funding.

\section{References}

[1] K. Bunse, M. Vodicka, P. Schönsleben, M. Brülhart, and F. Ernst, "Integrating energy efficiency performance in production management - gap analysis between industrial needs and scientific literature," Journal of Cleaner Production, vol. 19, no. 6-7, pp. 667-679, 2011.

[2] A. V. H. Sola and J. L. Kovaleski, "Eficiência energética nas indústrias: cenários e oportunidades," XXIV Encontro Nacional de Engenharia de Produção", 2004.

[3] A. B. Strapasson, "A energia térmica e o paradoxo da eficiência energética: Desafios para um novo modelo de planejamento energético," Master's thesis, Universidade de São Paulo, 2004.

[4] F. A. M. LINO and K. A. R. ISMAIL, "Energy and environmental potential of solid waste in brazil." in Energy Policy, vol. 39, no. 6, http://www.sciencedirect.com/science/article/pii/S030142151100228X, 2011.

[5] ABNT ISO 50001: sistemas de gestão de energia - requisitos com orientações para uso, ASSOCIAÇÃO BRASILEIRA DE NORMAS TÉCNICAS, Rio de Janeiro, 2011.

[6] A. Wessels, "Energy management system implementation at toyota sa," in Industrial and Commercial Use of Energy (ICUE), 2011 Proceedings of the 8th Conference on the, aug. 2011, pp. $40-45$.

[7] E. Jordanger, B. H. Bakken, A. T. Holen, A. Helseth, and A. Botterud, "Energy distribution system planning -methodologies and tools for multi-criteria decision analysis," in Electricity Distribution, 2005. CIRED 2005. 18th International Conference and Exhibition on, june 2005, pp. $1-5$.

[8] Y.-j. He, J. Ge, and L.-z. Zhang, "Analysis of several neglected issues of energy situation and suggestions on the energy stratagem," in 2011 Asia-Pacific Power and Energy Engineering Conference. IEEE, Mar. 2011, pp. 1-4. [Online]. Available: http://dx.doi.org/10.1109/APPEEC.2011.5748398 